\title{
Factors associated with body mass index in adults from Northern Greece
}

\author{
Themistoklis Tzotzas ${ }^{1}$, Theodoros Konstantinidis ${ }^{2}$, Maria Bougoulia ${ }^{1}$, \\ Gerasimos E. Krassas ${ }^{1}$
}

${ }^{1}$ Department of Endocrinology, Diabetes and Metabolism, Panagia General Hospital, Thessaloniki, Greece, ${ }^{2}$ Department of Hygiene and Statistics, Dimokritio University of Thrace, Thrace-Greece

\begin{abstract}
The aim of this large scale epidemiological cross-sectional study was to investigate potential factors, such as age, gender, socioeconomic status (measured as educational level and profession), smoking habits and physical activity, that could influence Body Mass Index (BMI) in a large sample of Greeks of Central Macedonia. Overall, 4032 adults (1296 males and 2736 females), age: 44.3 \pm 14.5 y (mean \pm SD) participated in this study. Candidates were contacted by phone and provided self-reported data about their age, weight, height, socioeconomic status, smoking habits and physical activity. Our results showed that the mean BMI value was $26.2 \pm 5(\times \pm S D)$. Factors associated with BMI were age (positively), physical activity and education level (negatively) in both genders and smoking habits (negatively) only in women. Obesity prevalence was higher in females, and in middle age, in civil employees, less educated and non-smoking subjects of both genders while overweight prevalence was higher in males, and in old age, in less educated and non-smoking subjects of both genders. In conclusion, several environmental factors were found to be associated with obesity or overweight indices in our sample of Greek individuals.
\end{abstract}

Key words: Body mass index, Northern Greece, Adults, Factors

\section{INTRODUCTION}

Obesity is an increasing health problem associated with serious clinical consequences and high mortality rates. Its prevalence is on the rise in most developed countries and, according to WHO, current

Address correspondence and requests for reprints to: Prof. G.E. Krassas, Associate Professor of Medicine Chairman, Department of Endocrinology, Diabetes and Metabolism, Panagia General Hospital, N. Plastira 22 Thessaloniki - Greece 551 32, Tel. 0030 2310-447-444, Fax: 0030 2310-282-476, e-mail: krassas@the.forthnet.gr Received 26-01-04, Revised 15-03-04, Accepted 20-03-04 prevalence rates are about 20-25\% in American adults and $15-20 \%$ in Europeans ${ }^{1}$.

In Greece, some reports show that the prevalence of obesity is high among both children and adults ${ }^{2-4}$. In a recent survey in Central Macedonia, Northern Greece, we found that the prevalence of overweight and obesity in adults was $35.4 \%$ and $19.9 \%$, respectively ${ }^{5}$.

Body weight is influenced by both genetic and environmental parameters. Various studies worldwide have shown the determining role of environmental factors, such as dietary and physical activity habits, 
educational level, profession, smoking habits etc., in the prevalence of obesity ${ }^{6,7}$. Only a few studies, however, have examined the association of such factors with obesity in Greek adults ${ }^{8-10}$.

The aim of this epidemiological cross-sectional study was to investigate the effect of factors such as age, gender, socioeconomic status (SES), smoking habits (SH) and physical activity (PA) on Body Mass Index (BMI) in a large sample of Greeks in Central Macedonia.

\section{SUBJECTS AND METHODS}

Overall, 4032 adults [1296 males (M), 2736 females (F)] aged $44.3 \pm 14.5$ years $(\bar{x} \pm S D)$ participated in this survey, which was conducted in Central Macedonia. The survey was part of a large-scale epidemiological study carried out in large areas of Greece, Serbia and Turkey with the aim of providing self-reported data about obesity prevalence in these countries. Data concerning methodology have been presented in a previous publication ${ }^{5}$. Potential participants were contacted by phone by selection of every $5^{\text {th }}$ person in the telephone directory. After having the purpose of the study explained to them, they were invited to take part. The other selection criterion was the age (not over 70 or under 20 years). Pregnant women were also excluded from the study. Approximately $78 \%$ of the contacted persons agreed to participate.

For the purpose of the study, participants were asked questions about their age, weight, height, SES, $\mathrm{SH}$ and PA. Dependent and independent factors were categorized into groups as follows:

- Dependent factors: BMI was calculated as weight/ height ${ }^{2}\left(\mathrm{~kg} / \mathrm{m}^{2}\right)$ and was used as a continuous factor in the analysis. The data were also categorized according to WHO definitions of obesity for adults: normal weight (BMI: 18.5-24.9), overweight (BMI: 25.0-29.9) and obesity (BMI=30).

- Independent factors: Age was categorized into the following 10 groups: 20-24.9, 25-29.9, 30-34.9, 3539.9, 40-44.9, 45-49.9, 50-54.9, 55-59.9, 60-64.9, 6569.9 years.

Socioeconomic status was defined as attained educational level (EL) and current profession. This combination of the parameters "education and occupation" considers psychological characteristics including life quality and job strain as possible factors associated with weight. EL comprised 3 levels: (1) primary school level: 6 years of study, (2) high school level: 712 years of study and (3) university level: 13 years of study. Professional occupation was categorized into 5 groups: Civil Employee (CE), Private Employee (PE), Pensioner (PN), Student (St), Self-Employed (SE). In women, an extra category of Housekeeper $(\mathrm{H})$ was added.

The smoking habits group was divided into smokers (those who presently smoke at least one cigarette per day), non-smokers (those who had never smoked cigarettes regularly) and ex-smokers (those who used to smoke and discontinued smoking at least 6 months before the initiation of this study). Due to the fact that the vast majority of ex-smokers $(96 \%)$ reported smoking cessation for more than 2 years and the number of ex-smokers was small, this group was incorporated into the group of non-smokers.

Physical activity also comprised 2 levels: regular exercise (2-7 days/week) and absence of exercise $(<1$ day/week).

\section{STATISTICAL ANALYSIS}

We established a database so that the accuracy of each parameter could be easily controlled. Subsequently, we tested if normal distribution goodness accorded with all quantitative factors existing by using the Kolmogorov-Smirnov test. All factors of the study were found to fit normal distribution. Means and standard deviation scores $(\bar{x} \pm \mathrm{SD})$ were calculated for each factor. For univariate analysis, we used the Student's t-test or ANOVA for independent samples. We also performed logistic regression models to evaluate the associations between dependent factors [overweight (OW), obesity (OB)] and independent factors (age, gender, EL, PR, PA, SH). We thus calculated adjusted odds ratios (OR) and $95 \%$ confidence intervals $(95 \% \mathrm{CI})$ for being overweight and obese. The statistical package for Social Sciences (SPSS for Windows, v 12, 2000) was used for all statistical analyses. Values of $\mathrm{P}<0.05$ were considered statistically significant.

\section{RESULTS}

The mean BMI in the entire cohort was $26.2 \pm 5.0$ $(\bar{x} \pm \mathrm{SD}), 26.2 \pm 3.6$ in men and $26.3 \pm 5.6$ in women, 
Table 1. Mean BMI values in the different categories of the factors studied

\begin{tabular}{|c|c|c|c|c|}
\hline & & $\begin{array}{c}\text { BMI (men) } \\
\bar{x} \pm \text { SD }\end{array}$ & $\begin{array}{c}\text { BMI (women) } \\
\bar{x} \pm \text { SD }\end{array}$ & $\begin{array}{c}\text { P* } \\
\text { NS to Physical activity row }\end{array}$ \\
\hline \multirow[t]{11}{*}{ Age (years) } & $20.0-24.9$ & $23.6 \pm 2.7$ & $21.6 \pm 3.1$ & $<0.001$ \\
\hline & $25.0-29.9$ & $24.6 \pm 2.5$ & $22.7 \pm 3.8$ & $<0.001$ \\
\hline & $30.0-34.9$ & $25.8 \pm 3.4$ & $24.4 \pm 4.5$ & $<0.01$ \\
\hline & 35.0-39.9 & $26.4 \pm 4.1$ & $25.6 \pm 5.2$ & NS \\
\hline & $40.0-44.9$ & $26.7 \pm 4.1$ & $26.4 \pm 5.5$ & NS \\
\hline & $45.0-49.9$ & $26.6 \pm 3.5$ & $28.2 \pm 5.9$ & $<0.01$ \\
\hline & $50.0-54.9$ & $27.2 \pm 3.5$ & $28.2 \pm 5.7$ & NS \\
\hline & $55.0-59.9$ & $27.8 \pm 3.1$ & $29.8 \pm 5.3$ & $<0.001$ \\
\hline & $60.0-64.9$ & $26.8 \pm 3.5$ & $27.9 \pm 4.8$ & $<0.05$ \\
\hline & $65.0-69.9$ & $27.5 \pm 3.7$ & $29.0 \pm 5.6$ & $<0.05$ \\
\hline & & $\mathrm{P}<0.001$ & $\mathrm{P}<0.001$ & \\
\hline \multirow[t]{4}{*}{ Education (years of study) } & $00-06$ & $27.6 \pm 4.6$ & $27.8 \pm 4.9$ & NS \\
\hline & $07-12$ & $26.2 \pm 3.3$ & $27.1 \pm 6.0$ & $<0.001$ \\
\hline & $\geq 13$ & $25.4 \pm 3.2$ & $23.0 \pm 3.9$ & $<0.001$ \\
\hline & & $\mathrm{P}<0.001$ & $\mathrm{P}<0.001$ & \\
\hline \multirow[t]{3}{*}{ Smoking status } & Non-smokers & $26.4 \pm 3.5$ & $26.8 \pm 5.7$ & $<0.001$ \\
\hline & Smokers & $25.9 \pm 3.8$ & $25.1 \pm 5.4$ & $<0.001$ \\
\hline & & NS & $\mathrm{P}<0.001$ & \\
\hline \multirow[t]{3}{*}{ Physical activity } & Non-exercised & $26.5 \pm 3.8$ & $26.9 \pm 5.8$ & \\
\hline & Exercised & $25.4 \pm 3.1$ & $23.9 \pm 4.2$ & $<0.01$ \\
\hline & & $\mathrm{P}<0.001$ & $\mathrm{P}<0.001$ & \\
\hline \multirow[t]{6}{*}{ Profession } & Civil Employee & $26.6 \pm 3.6$ & $26.5 \pm 5.3$ & NS \\
\hline & Private Employee & $26.3 \pm 3.7$ & $24.7 \pm 4.8$ & $<0.001$ \\
\hline & Housekeeper & - & $26.4 \pm 5.4$ & \\
\hline & Pensioner & $26.9 \pm 3.4$ & $27.7 \pm 4.7$ & $<0.05$ \\
\hline & Student & $23.4 \pm 3.4$ & $21.1 \pm 2.6$ & $<0.001$ \\
\hline & Self-Employed & $26.4 \pm 3.5$ & $25.1 \pm 4.8$ & $<0.001$ \\
\hline
\end{tabular}

$\mathrm{P}$ (ANOVA): for comparison between categories of each factor, $\mathrm{P}^{*}$ (Student's t-test): for comparison of factors between males and females NS: Non Significant

respectively.

\section{Factors associated with BMI}

Table 1 depicts the means of BMI according to determinant factors for both genders. BMI increased with age from the younger groups to the 55-59.9 group followed by a decrease in the group 60-64.9 and an increase in the older groups in both men and women. In younger ages (up to 45 years old), men's BMI levels were higher than women's, while the opposite was observed for the older age groups.

An inverse relationship was observed between years of education and BMI in both genders. Compared to men, BMI levels were higher in women with the exception of the groups of the lowest educational level.

Concerning smoking habits, no relationship with BMI was found in males, while in females a negative correlation between smoking habits and BMI was noticed.

BMI was higher in non-exercised individuals than in exercised, both in men and in women. For nonexercised groups, no statistical difference between BMI in the two genders was found, while for exer- 
cised individuals BMI was higher in men.

In the factor "profession", the higher BMI was found in pensioners and the lower in students of both genders. In all groups of professions, men had higher BMI than women with the exception of pensioners. The BMI of civil employees was similar in both genders.

\section{Factors associated with overweight and obesity prevalence}

Table 2 shows percentages of OW and OB by the factors studied.
OW prevalence in men increased steadily from the younger groups until 40 years of age, where it reached $56.7 \%$. Then it remained steady at 54-58\% until 65 years when it fell to $52 \%$. In contrast, women showed an almost constant increase of OW percentage by age reaching $47 \%$ between $60-64.9$ years. Thereafter, a rapid fall to a level of $35 \%$ was observed. OW prevalence was higher in men than in women in all age, groups. OB prevalence in both genders increased constantly until the age of 60 where it peaked at $22 \%$ for men and $47.4 \%$ for women. Contrary to the findings

Table 2. Percentages of overweight (OW) and obesity $(\mathrm{OB})$ in the different categories of the factors studied

\begin{tabular}{|c|c|c|c|c|c|c|c|}
\hline & & \multicolumn{2}{|c|}{ Men } & \multicolumn{2}{|c|}{ Women } & \multirow[b]{2}{*}{$\mathbf{P}^{*}(\mathrm{OW})$} & \multirow[b]{2}{*}{$\mathbf{P} * *(\mathbf{O B})$} \\
\hline & & ow\% & $\mathrm{OB} \%$ & OW\% & OB\% & & \\
\hline \multirow[t]{10}{*}{ Age (years) } & $20.0-24.9$ & 24.7 & 1.9 & 10.7 & 1.6 & $<0.001$ & NS \\
\hline & $25.0-29.9$ & 40.4 & 1.9 & 19.2 & 4.1 & $<0.001$ & NS \\
\hline & $30.0-34.9$ & 48.4 & 10.2 & 20.0 & 14.3 & $<0.001$ & NS \\
\hline & $35.0-39.9$ & 56.7 & 12.0 & 27.7 & 17.0 & $<0.001$ & NS \\
\hline & $40.0-44.9$ & 56.5 & 12.9 & 27.8 & 22.4 & $<0.001$ & $<0.05$ \\
\hline & $45.0-49.9$ & 54.1 & 11.3 & 29.2 & 36.2 & $<0.001$ & $<0.001$ \\
\hline & $50.0-54.9$ & 54.3 & 17.1 & 36.8 & 33.6 & $<0.01$ & $<0.01$ \\
\hline & $55.0-59.9$ & 58.3 & 21.9 & 30.6 & 47.4 & $<0.001$ & $<0.001$ \\
\hline & $60.0-64.9$ & 56.0 & 18.3 & 47.7 & 26.4 & NS & NS \\
\hline & $65.0-69.9$ & 52.1 & 20.2 & 34.8 & 39.9 & $<0.01$ & $<0.001$ \\
\hline \multirow{4}{*}{$\begin{array}{l}\text { Education } \\
\text { (years of study) }\end{array}$} & 00-06 & 49.2 & 24.4 & 44.3 & 27.6 & NS & NS \\
\hline & $07-12$ & 54.0 & 10.0 & 24.5 & 30.2 & $<0.001$ & $<0.001$ \\
\hline & ${ }^{3} 13$ & 46.1 & 6.7 & 19.5 & 6.0 & $<0.001$ & NS \\
\hline & & $\mathrm{P}<0.05$ & $\mathrm{P}<0.001$ & \multicolumn{2}{|c|}{$\mathrm{P}<0.001$} & & \\
\hline \multirow[t]{3}{*}{ Smoking status } & Non-smokers & 50.8 & 11.6 & 29.7 & 24.6 & $<0.001$ & $<0.001$ \\
\hline & Smokers & 49.1 & 12.2 & 24.2 & 20.0 & $<0.001$ & $<0.001$ \\
\hline & & \multicolumn{2}{|c|}{ NS } & \multicolumn{2}{|c|}{$\mathrm{P}<0.001$} & & \\
\hline \multirow[t]{3}{*}{ Physical activity } & Non-exercised & 51.5 & 13.8 & 29.4 & 28.3 & $<0.001$ & $<0.001$ \\
\hline & Exercised & 47.5 & 7.5 & 23.7 & 8.3 & $<0.001$ & $<0.001$ \\
\hline & & NS & $\mathrm{P}<0.001$ & \multicolumn{2}{|c|}{$\mathrm{P}<0.001$} & & \\
\hline \multirow[t]{6}{*}{ Profession } & Civil Employee & 56.1 & 12.2 & 29.9 & 24.3 & $<0.001$ & $<0.001$ \\
\hline & Private Employee & 47.0 & 13.6 & 24.8 & 14.5 & $<0.001$ & NS \\
\hline & Housekeeper & - & - & 35.4 & 19.9 & & \\
\hline & Pensioner & 58.6 & 13.9 & 44.0 & 27.0 & $<0.001$ & $<0.001$ \\
\hline & Student & 22.4 & 2.4 & 9.6 & 0.6 & $<0.001$ & $<0.01$ \\
\hline & Self-Employed & 56.3 & 10.8 & 23.8 & 18.5 & $<0.001$ & $<0.001$ \\
\hline
\end{tabular}

$\mathrm{P}(\mathrm{ANOVA})$ : for comparison between categories of each factor,

$\mathrm{P}^{*}$ (Student's t-test): for comparison of factors between OW males and females

$\mathrm{P}^{* *}$ (Student's t-test): for comparison of factors between OB males and females

NS: Non significant 
concerning OW prevalence, $\mathrm{OB}$ prevalence was always higher in women in all age groups.

For educational level, there was a clear gradient for the attained level of education and the percentage of OW and OB between the $2^{\text {nd }}$ and $3^{\text {rd }}$ groups in both genders. In men a clear negative association between OB\% and years of study was found, while in women a negative association between $\mathrm{OW} \%$ and years of study was observed. OW and OB prevalence was higher in pensioners and lower in students of both genders.

Concerning smoking habits, women who smoked were significantly less overweight and obese than those who did not smoke, while in men no such relationship was observed.
Women who were exercising were less overweight than those who did not exercise, while for both genders physical activity was negatively related to obesity prevalence.

Table 3 shows multivariate analysis, which was performed to identify independent correlates of OW and OB prevalence. Concerning OW prevalence, the analysis confirmed the strong influence of age (doubling of risk for those over 35 years), of gender (relative risk [RR] at 0.36 for females compared to males), and the weaker but significant influences of educational level (relative risk of 0.77 for individuals with more than 6 years of study in comparison to those with primary school education) and of smoking habits (relative risk 0.83 for smokers in comparison to non-smokers). Among different professions, students had the

Table 3. Odds Ratios and 95\% CI of the factors associated with overweight and obesity

\begin{tabular}{|c|c|c|c|c|}
\hline & & & & \\
\hline & OR & $95 \% \mathrm{CI}$ & OR & $95 \% \mathrm{CI}$ \\
\hline Age (years) & & & & \\
\hline$<35$ & 1.0 & (ref) & 1.0 & (ref) \\
\hline $35-49$ & 1.56 & $1.26-1.92$ & 3.85 & $2.71-5.48$ \\
\hline $50-64$ & 2.0 & $1.55-2.57$ & 5.84 & $3.95-8.63$ \\
\hline $65+$ & 1.75 & $1.22-2.49$ & 4.3 & $2.6-7.08$ \\
\hline Education (years of stu & & & & \\
\hline$<7$ & 1.0 & (ref) & 1.0 & (ref) \\
\hline $7-12$ & 0.78 & $0.64-0.96$ & 0.94 & $0.74-1.2$ \\
\hline $13+$ & 0.76 & $0.59-0.98$ & 0.38 & $0.27-0.55$ \\
\hline Physical activity & & & & \\
\hline Non-Exercised & 1.0 & (ref) & 1.0 & (ref) \\
\hline Exercised & 0.85 & $0.72-1.01$ & 0.41 & $0.31-0.54$ \\
\hline Smoking status & & & & \\
\hline Non-Smokers & 1.0 & (ref) & 1.0 & (ref) \\
\hline Smokers & 0.83 & $0.72-0.95$ & 0.85 & $0.69-1.05$ \\
\hline Gender & & & & \\
\hline Male & 1.0 & (ref) & 1.0 & (ref) \\
\hline Female & 0.36 & $0.31-0.43$ & 1.82 & $1.45-2.29$ \\
\hline Profession & & & & \\
\hline Civil Employee & 1.0 & (ref) & 1.0 & (ref) \\
\hline Private Employee & 0.77 & $0.59-1.01$ & 0.67 & $0.47-0.96$ \\
\hline Housekeeper & 0.92 & $0.67-1.26$ & 0.41 & $0.27-0.61$ \\
\hline Pensioner & 1.0 & $0.70-1.42$ & 0.54 & $0.35-0.83$ \\
\hline Student & 0.36 & $0.23-0.55$ & 0.33 & 0.11-0.99 \\
\hline Self-Employed & 0.86 & $0.65-1.14$ & 0.67 & $0.46-0.98$ \\
\hline
\end{tabular}


lowest relative risk (0.36). For OB prevalence, a strong influence of the following factors was documented: age (RR 5.8 times higher for individuals 50-64 in comparison to those $<35$ years), gender (RR 1.82 for females in comparison to males), educational level ( 0.38 for secondary school education in comparison to those with primary school education), and physical activity status ( 0.41 for exercised group). A weaker but statistically significant influence was found for smoking habits ( 0.85 for smokers). For the "profession" category, civil employees were more obese than other profession, after adjustment for age and gender.

\section{DISCUSSION}

In the present study some interesting associations emerged between prevalence of overweight, obesity and BMI, and age, gender, socioeconomic status and lifestyle factors in a large population of Northern Greece.

Socioeconomic status is a complex factor that is commonly ascertained by one or more simple indicators such as education, income, profession, place of residence etc ${ }^{7}$. In our study SES was measured as the highest attained educational level and professional occupation, which was categorized into 5 common jobs. When SES was measured as EL, a graded inverse relationship between SES and BMI and overweight prevalence in both genders, regardless of other factors, was observed. The negative association was more pronounced in obese males than in obese females, while the opposite was true of overweight subjects. When SES was measured by the indicator occupation, it was found, after adjustment for the other factors, that public employees were the most obese of any professional group and students were those the least overweight.

Numerous studies have investigated the relationship between socioeconomic status and obesity prevalence ${ }^{12,13}$. In most of them, educational level was used as an indicator for SES ${ }^{12,14}$. In developed societies, a strong inverse relationship has been observed, mainly among women, while in developing ones a positive association has been found in both genders and in children. The results of the present study are in agreement with those prevailing in affluent societies, with the exception that our obese population, mostly men are less educated. In our Mediterranean society, this fact probably reflects the patriarchal view of body image of lesser educated individuals.

Regarding "occupation", the usual factors used for this component are present employment status, number of working hours, income, etc ${ }^{15-16}$. Usually, an inverse association is found between low employment groups and obesity ${ }^{17,18}$. In the present study, where we grouped different professional categories, public employees were more obese than others. This association cannot be interpreted by the present analysis but it could be explained by the lack of physical activity in such individuals.

To the best of our knowledge, there is only one published study that investigated the relationship of SES with OB in a sample of Greek participants. This was a large Pan-European study of 15,239 individuals where it was concluded that people of high social class with higher educational level were less likely to be obese? $^{\text {. }}$.

It remains unclear which factors may mediate the influence of SES on obesity and thinness. In a comprehensive review of 144 studies, Sobal and Stunkard suggested that such factors include dietary restraint, physical activity, social mobility and heredity ${ }^{13}$.

Concerning smoking habits, numerous epidemiological studies have shown that smokers have relatively lower body weight and that giving up smoking often leads to weight gain ${ }^{19-21}$. The relationship between $\mathrm{SH}$ and BMI could be mediated by the action of nicotine as an appetite suppressant or by the thermogenetic effect of smoking. Recently, it was reported that smokers had a higher resting energy expenditure by $68 \mathrm{kcal} /$ day than non-smokers ${ }^{22}$. In our study, only women of all ages showed the inverse association between smoking and BMI or OB prevalence. This discrepancy could be a sample effect or due to other confounding factors such as physical activity and education. The issue of this modifying effect of education was already addressed by Mollarius and Seidell in a study of 36,000 Dutch men and women ${ }^{23}$. The association between smoking and body weight was found to differ according to the degree of education, particularly in men. Male heavy smokers of a high educational level had higher BMI than non-smokers. No clear-cut explanation can be provided for this finding but the possibility of other factors involved in the whole process (e.g. clustering of unhealthy habits in male heavy smokers, 
role of stress, etc) cannot be excluded. Moreover, the effect of different confounding factors in our study cannot be ruled out since in multiple regression analysis and after adjustment of other factors, $\mathrm{SH}$ were inversely related, although weakly, to OW and OB prevalence in the whole population. Notably, Marti et al. reported that an inverse association between smoking and body weight exists only in populations with a high prevalence of smoking ${ }^{24}$.

The relationship between physical activity and weight parameters has been studied extensively, but most data are contradictory. Cross-sectional associations between PA and BMI are strong, while associations seen in populations which have been studied longitudinally are typically low ${ }^{25}$. Our cross-sectional data showed an inverse association between reported PA levels, BMI and obesity prevalence in both genders, but no such association was found between PA and OW prevalence in men. This difference is probably due to the smaller number of male individuals investigated or to a gender difference in the type of PA. A less consistent association between levels of PA and body weight parameters in men was also pointed out in similar studies ${ }^{26,27}$. Additionally, in the model of multiple regression analysis, the reported PA was not confirmed as an independent factor of OW prevalence. Possibly other factors are involved, although to a lesser extent, in the pathogenesis of increased weight seen in our OW population.

The influence of physical activity on BMI was extensively assessed in the Greek sample of the study of EPIC, where occupational activities (OA) and leisuretime physical activities (LTPA) were measured $^{8}$. A strong inverse association between energy expenditure and BMI was found, and increasing PA appears to be half as effective in reducing BMI as decreasing energy intake. In the Seven Countries Study, an international study with Greek participants from the islands of Corfu and Crete, a strong inverse relationship was documented between job-related PA and body fat indices ${ }^{10}$. Interestingly, King et al., comparing OA with LTPA in the likelihood of obesity, found a more important role of OA than LTPA in preventing obesity ${ }^{28}$. Individuals with high OA were less likely to be obese by $42 \%$ even without participation in any LTPA.

The effect of age and gender on BMI and OW and OB prevalence in our study is similar to that observed in other Greek and international studies ${ }^{7,8}$. We found a steady increase of BMI in both genders until the age of 60 , with men having higher BMI in younger ages, and women in older ages. Overall, the prevalence of $\mathrm{OW}$ and $\mathrm{OB}$ increased until the age of 65 years, but odds ratios were higher in $\mathrm{OB}$ than $\mathrm{OW}$ status. It should be remembered that BMI is not a reliable measure of adiposity in old age because a decrease during this period often reflects a decrease in lean body mass rather than fat mass. We also found that more women than men tended to be obese whereas the inverse was true of the overweight population. This phenomenon can be observed in other countries which differ in many ways, such as England, Mauritius, Japan and Saudi Arabia ${ }^{8}$.

There are, however, some methodological drawbacks in our study, which have to be taken into account before we reach final conclusions. Its major limitation is the use of self-reported, telephone based data. This issue mainly concerns reported height and weight where it is known that both men and women tend to underestimate their weight and overestimate their height. Recent studies concerning the accuracy of self-reported data found a discrepancy between those and the measured data ${ }^{29}$, while earlier studies reached an opposite conclusion ${ }^{30,31}$. Also, there could have been misreporting on some of the determinant factors of BMI in our study (e.g. physical activity, smoking habits), leading to some degree of misclassification for the different categories. Another limitation is the cross-sectional design of the study, which does not provide evidence for the causal nature of the association between the studied factors and BMI. Moreover, for the purposes of rapidity and accuracy, a fairly simplified model of categorization of some factors, like SH and PA, was chosen. Moreover, for practical reasons, questions on food habits were not included, although we were aware of the possible influence of this factor on the observed associations. Finally, the use of the telephone directory for selection purposes may exclude individuals from lower socioeconomic groups who might not have access to this facility.

On the other hand, the major strengths of the study are the large number of subjects, the relatively high response rate and the good representativity of the geographic area studied. This study, while not etiological in nature, is one of the very few in Greece that 
provides some interesting findings on the associations between environmental factors and obesity indices.

In conclusion, in the Greek population studied we found that factors associated with BMI are age (positively), physical activity and educational level (negatively) in both genders and smoking habits (negatively) only in women. OB prevalence is more frequent in females, and in middle age, in civil employees, less educated and non-smoking subjects of both genders, while $\mathrm{OW}$ prevalence is more frequent in males, and in old age, in less educated and non-smoking subjects of both genders.

Our findings may help in designing intervention measures for prevention and/or management of obesity.

\section{REFERENCES}

1. World Health Organization, 1998 Obesity: Preventing and Managing the Global Epidemic. Report of a WHO consultation on obesity. WHO publ, Geneva.

2. Mamalakis G, Kafatos A, 1996 Prevalence of obesity in Greece. Int J Obes Relat Metab Disord 20: 488-492.

3. Krassas GE, Tzotzas Th, Tsametis Ch, Konstantinidis Th, 2001 Prevalence and trends in overweight and obesity among children and adolescents in Thessaloniki, Greece. J Pediatr Endocrinol Metab 14: 1319-1326.

4. Bertsias G, Mammas I, Linardakis M, Kafatos A, 2003 Overweight and obesity in relation to cardiovascular risk factors among medical students in Crete, Greece. BMC Public Health 3: 3-11.

5. Krassas GE, Kelestimur F, Micic M, et al, 2003 Self-reported prevalence of obesity among 20,329 adults from large territories of Greece, Serbia and Turkey. Hormones 2: 49-54.

6. Pomerleau J, McKeigue PM, Chaturvedi N, 1999 Factors associated with obesity in South Asian, Afro-Caribbean and European women. Int $\mathbf{J}$ Obes Relat Metab Disord 23: 25-33.

7. Antipatis VJ, Gill TP 2001 Obesity as a Global Problem In: Björntorp P (ed) International Textbook of Obesity, UK: John Wiley and Sons Ltd; pp, 3-22.

8. Trichopoulou A, Gnardellis C, Lagiou A, Benetou V, Trichopoulos D, 2000 Body mass index in relation to energy intake and expenditure among adults in Greece. Epidemiology 11: 333-336.

9. Martinez JA, Kearney JM, Kafatos A, Paquet S, Martinez-Gonzalez MA, 1999 Factors independently associated with self-reported obesity in the European Union. Public Health Nutr 2: 125-133.

10. Kromhout D, Bloemberg B, Seidell JC, Nissinen A, Menotti A, 2001 Physical activity and dietary fiber determine population body fat levels: the Seven Countries
Study. Int J Obes Relat Metab Disord 25: 301-306.

11. Paeratakul S, Lovejoy JC, Ryan DH, Bray GA, 2002 The relation of gender, race and socioeconomic status to obesity and obesity comorbidities in a sample of US adults. Int J Obes Relat Metab Disord 26: 1205-1210.

12. Sundquist J, Johanson SE, 1998 The influence of socioeconomic status, ethnicity and lifestyle on body mass index in a longitudinal study. Int J Epidemiol 27: 57-63.

13. Sobal J, Stunkard AJ, 1989 Socioeconomic status and obesity: a review of the literature. Psychol Bull 105: 260275.

14. Molarius A, Seidell JC, Sans S, Tuomilehto J, Kuulasmaa K, 2000 Educational level, relative body weight, and changes in their association over 10 years: An international perspective from the WHO MONICA project. Am J Public Health 90: 1260-1268.

15. Ball K, Mishra G, Crawford D, 2002 Which aspects of socioeconomic status are related to obesity among men and women? Int J Obes Relat Metab Disord 26: 559-565.

16. Wamala SP, Wolk A, Orth-Gomer K, 1997 Determinants of obesity in relation to socioeconomic status among middle-aged Swedish women. Prev Med 26: 734-744.

17. Van Lenthe FJ, Droomers M, Schrijvers CTM, Mackenbach JP, 2000 Socio-demographic factors and 6 years change in body mass index: longitudinal results from the GLOBE study. Int J Obes Relat Metab Disord 24: 10771084.

18. Lahmann PH, Lissner L, Gullberg B, Berglund G, 2000 Sociodemographic factors associated with long-term weight gain, current body fatness and central adiposity in Swedish women. Int J Obes Relat Metab Disord 24: 685694.

19. Albanes D, Jones DY, Micozzi MS, Mattson ME, 1987 Associations between smoking and body weight in the US population: analysis of NHANES II. Am J Public Health 77: 439-444.

20. Lissner L, Bengtsson C, Lapidus L, Bjorkelund C, 1992 Smoking initiation and cessation in relation to body fat distribution based on data from a study of Swedish women. Am J Public Health 82: 273-275.

21. Flegal KM, Troiano RP, Pamuk ER, Kuczmarski RJ, Campbell SM, 1995 The influence of smoking cessation on the prevalence of overweight in the United States. N Eng J Med 333: 1165-1170.

22. Kimm SYS, Glynn NW, Aston CE, Poehiman ET, Daniels SR, 2001 Effects of race, cigarette smoking, and use of contraceptive medications on testing energy expenditure in young women. Am J Epidemiol 154: 718-724.

23. Molarius A, Seidell JC, 1997 Differences in the association between smoking and relative body weight by level of education. Int J Obes Relat Metab Disord 21: 189-196.

24. Marti B, Tuomilehto J, Korhonen HJ, et al, 1989 Smoking and leanness: evidence for change in Finland. BMJ 298: 1287-1290.

25. Saris WHM, Blair SN, van Baak MA, et al, 2003 How much physical activity is enough to prevent unhealthy weight gain? Outcome of the IASO $1^{\text {st }}$ Stock conference and consensus statement. Obes Rev 4: 101-114. 
26. Ball K, Owen N, Salmon J, Bawman A, Gore CJ, 2001 Association of physical activity with body weight and fat in men and women. Int J Obes Relat Metab Disord 25: 914-919.

27. Salmon J, Owen N, Bawman A, Schmitz MKH, Booth M, 2000 Leisure-time, occupational and household physical activity among professional, skilled and less-skilled workers, and homemakers. Prev Med 30: 191-199.

28. King GA, Fitzhugh EC, Bassett DR, et al, 2001 Relationship of leisure-time physical activity and occupational activity to the prevalence of obesity. Int J Obes Relat Metab Disord 25: 606-612.

29. Niedhammer I, Bugel I, Bonenfant S, Goldberg M, Leclerc A, 2000 Validity of self-reported weight and height in the French GAZEL cohort. Int J Obes Metab Disord 24: 1111-1118.

30. Rowland ML, 1990 Self-reported weight and height. Am J Clin Nutr 52: 1125-1133.

31. Bowman RL, Delucia JL, 1992 Accuracy of self-reported weight: a meta-analysis. Behav Ther 23: 637-655. 